\title{
A comparative study on the antioxidant activity of methanolic extracts from different parts of Morus alba L. (Moraceae)
}

\author{
Muhammad Ali Khan', Aziz Abdur Rahman', Shafiqul Islam', Proma Khandokhar², Shahnaj Parvin, \\ Md Badrul Islam³, Mosharrof Hossain ${ }^{4}$, Mamunur Rashid', Golam Sadik', Shamima Nasrin?, \\ M Nurul Haque Mollah ${ }^{5}$ and AHM Khurshid Alam ${ }^{1 *}$
}

\begin{abstract}
Background: Antioxidants play an important role to protect damage caused by oxidative stress (OS). Plants having phenolic contents are reported to possess antioxidant properties. The present study was designed to investigate the antioxidant properties and phenolic contents (total phenols, flavonoids, flavonols and proanthrocyanidins) of methanolic extracts from Morus alba (locally named as Tut and commonly known as white mulberry) stem barks (TSB), root bark (TRB), leaves (TL) and fruits (TF) to make a statistical correlation between phenolic contents and antioxidant potential.

Methods: The antioxidant activities and phenolic contents of methanolic extractives were evaluated by in vitro standard method using spectrophotometer. The antioxidant activities were determined by total antioxidant capacity, DPPH (1,1-diphenyl-2-picrylhydrazine) radical scavenging assay, hydroxyl radical scavenging assay, ferrous reducing antioxidant capacity and lipid peroxidation inhibition assay methods.

Results: Among the extracts, TSB showed the highest antioxidant activity followed by TRB, TF and TL. Based on DPPH and hydroxyl radical scavenging activity, the TSB extract was the most effective one with $I_{50} 37.75$ and $58.90 \mathrm{\mu g} / \mathrm{mL}$, followed by TRB, TF and TL with $I_{50} 40.20$ and 102.03; 175.01 and 114.63 and 220.23 and $234.63 \mu \mathrm{g} / \mathrm{mL}$, respectively. The TSB extract had the most potent inhibitory activity against lipid peroxidation with $\mathrm{IC}_{50} 145.31 \mathrm{\mu g} / \mathrm{mL}$. In addition, the reducing capacity on ferrous ion was in the following order: TSB $>$ TRB $>$ TL > TF. The content of phenolics, flavonoids, flavonols and proanthocyanidins of TSB was found to be higher than other extractives.

Conclusion: The results indicate high correlation and regression ( $p$-value $<0.001$ ) between phenolic contents and antioxidant potentials of the extracts, hence the Tut plant could serve as effective free radical inhibitor or scavenger which may be a good candidate for pharmaceutical plant-based products. However, further exploration is necessary for effective use in both modern and traditional system of medicines.
\end{abstract}

Keywords: Morus alba, Moraceae, Oxidative stress, Antioxidant, Correlation and regression

\footnotetext{
* Correspondence: khurshid.jaist@gmail.com

'Department of Pharmacy, University of Rajshahi, Rajshahi 6205, Bangladesh

Full list of author information is available at the end of the article
} 


\section{Background}

Oxidative stress (OS) is the imbalance between cellular production of reactive oxygen species (ROS) and the ability of cells to scavenge them. OS has been implicated as a potential contributor to the pathogenesis of several diseases, such as cancer, diabetes and heart disease [1]. ROS cause the damage of many cellular components including lipids, proteins and nucleic acids, such as DNA leading to subsequent cellular death by modes of necrosis or apoptosis [2]. The damage can become more widespread due to weakened cellular antioxidant defense systems. All biological systems have antioxidant defense mechanism that protects against oxidative damages and repairs enzymes to remove damaged molecules. However, this natural antioxidant mechanism can be inefficient, hence dietary intake of antioxidant compounds is important. Consumption of fruits and vegetables is known to lower the risk of several diseases, such as cancer, cardiovascular diseases and stroke caused by OS [3] and such health benefits are mainly imposed due to the presence of phytochemicals, such as polyphenols, carotenoids and vitamin $\mathrm{E}$ and $\mathrm{C}$ [4].

Although the phenolic compounds are commonly found in both edible and non edible herbs, cereals, fruits, vegetables, oils, spices and other plant materials $[5,6]$, scientific information on antioxidant properties of endemic plants, limited to certain regions and known only by local populations, is still rather scarce. Therefore, the assessment of such properties remains an interesting and useful task, particularly to find new promising sources of natural antioxidants for functional foods and/or nutraceuticals [6,7].

Morus alba (locally known as Tut, commonly known as white mulberry, family: Moraceae) has been domesticated over thousands of years and adapted to the wide area of tropical, subtropical, and temperate zones of Asia, Europe, North and South America, Africa and India. It is extensively cultivated for leaf yield in sericulture [8]. Tut fruits contain phenolics and flavonoids contents, vitamin, fat (mainly linolic acid, palmitic acid, oleic acid) and minerals [9], and its leaves have fixed oil, carbohydrate, protein, tannin, alkaloids, sterol, flavonoids, glycosides and saponin [10,11]. Fruits, root and stem barks and leaves of Tut plant have been used in the treatment of inflammation, jaundice and hepatitis, cancer, diabetes, dislipidemia, diarrhoea, dyspepsia, edema, fever, headache, hypertension, purgative, anthelminthic and wounds [12-15]. Leaves of Tut plant have been reported to use in the treatment of depression, anxiety, cerebral ischemia, hepatic disease, cancer, diabetes, dislipidemia and ulcer [10,16-20]. However, there are only few reports on antioxidant activities of different parts of Tut plant. Therefore, in this study, we evaluated the comparative antioxidant activity of methanolic extractives from different parts of Tut plant and made a statistical correlation between phenolic contents and antioxidant activity.

\section{Methods}

Plant collection

Leaves, fruits, stem and root barks of Tut plant (Additional file 1: Figure S1) were collected from Rajshahi University campus, Rajshahi, Bangladesh, in May, 2011 and were identified by an expert taxonomist at the Department of Botany, University of Rajshahi. A voucher specimen was deposited to the herbarium in the Department of Botany, University of Rajshahi. Plant materials were then washed separately with fresh water to remove dirty materials and were shade dried for several days with occasional sun drying. The dried materials were ground into coarse powder by grinding machine and the materials were stored at room temperature for future use.

\section{Extract preparation}

According to our initial assessment we found methanol as the best solvent for the extraction of Tut plant. Initially, we did extraction using several solvents including methanol, ethanol, dichloromethane and ethyl acetate and based on TLC behavior and amount of extract obtained/gm of material we chose methanol for extraction.

The extraction was performed according to Alam et al. [21]. About $500 \mathrm{gm}$ of each powdered plant materials were taken in four amber colored reagent bottles and soaked the materials with 1.5 liter of methanol. The sealed bottles were kept for 15 days with occasional shaking and stirring. The final extracts were filtered seperately through cotton and then Whatman No.1 filter papers and was concentrated with a rotary evaporator under reduced pressure at $50^{\circ} \mathrm{C}$ to afford $30,35,45$ and $40 \mathrm{gm}$ extract of leaves, fruits, stem bark and root bark extract, respectively.

\section{Chemicals}

1,1-diphenyl-2-picrylhydrazyl (DPPH), potassium ferricyanide, catechin (CA), ferrous ammonium sulphate, butylated hydroxytoluene (BHT), gallic acid (GA), ascorbic acid (AA), $\mathrm{AlCl}_{3}$, trichloro acetic acid (TCA), sodium phosphate, ammonium molybdate, tannic acid, quercetin, DMSO, EDTA, acetyl acetone and $\mathrm{FeCl}_{3}$ were purchased from Sigma Chemical Co. (St. Louis, MO, USA); potassium acetate, phosphate buffer, thiobarbituric acid were purchased from Sigma-Aldrich, USA; vanillin was obtained from $\mathrm{BDH}$; folin-ciocalteus's phenol reagent and sodium carbonate were obtained from Merck (Damstadt, Germany). 


\section{Determination of total phenolics}

Total phenolic contents in the extracts were determined by the modified Folin-Ciocalteu method described by Wolfe et al., 2003 [22]. An aliquot of the extract was mixed with $2 \mathrm{ml}$ Folin-Ciocalteu reagent (previously diluted with water $1: 10 \mathrm{v} / \mathrm{v})$ and $2 \mathrm{ml}(75 \mathrm{~g} / \mathrm{l})$ of sodium carbonate. The tubes were vortexed for $15 \mathrm{sec}$ and allowed to stand for $20 \mathrm{~min}$ at $25^{\circ} \mathrm{C}$ for color development. Absorbance was then measured at $760 \mathrm{~nm}$ UVspectrophotometer (Shimadzu, USA). Samples of extract were evaluated at a final concentration of $0.1 \mathrm{mg} / \mathrm{mL}$. Total phenolic contents were expressed in terms of galic acid equivalent, GAE (standard curve equation: $\left.y=0.0086 x+0.0105, R^{2}=0.9997\right), m g$ of $G A / g$ of dry extract.

\section{Determination of total flavonoids}

Total flavonoids were estimated using method described by Ordon ez et al. [23]. To $0.5 \mathrm{ml}$ of sample, $1.5 \mathrm{ml}$ of methanol, $100 \mu \mathrm{l}$ of $10 \%$ aluminum chloride, $100 \mu \mathrm{l}$ of $1 \mathrm{M}$ potassium acetate solution and $2.8 \mathrm{ml}$ of distilled water was added. After one hour 30 minutes of incubation at room temperature (RT), the absorbance was measured at $420 \mathrm{~nm}$. Extract samples were evaluated at a final concentration of $0.1 \mathrm{mg} / \mathrm{mL}$. Total flavonoids content was expressed in terms of catechin equivalent, CAE (standard curve equation: $y=0.0135 x+0.0085$, $\left.\mathrm{R}^{2}=0.9984\right)$, $\mathrm{mg}$ of $\mathrm{CA} / \mathrm{g}$ of dry extract.

\section{Determination of total flavonols}

Total flavonols in the plant extracts were estimated using the method of Kumaran and Karunakaran [24]. To $2.0 \mathrm{ml}$ of sample (standard), $2.0 \mathrm{ml}$ of $2 \% \mathrm{AlCl}_{3}$ in ethanol and $3.0 \mathrm{ml}$ sodium acetate $(50 \mathrm{~g} / \mathrm{L})$ solutions were added. The absorption at $440 \mathrm{~nm}$ was read after 2.5 hours at $20^{\circ} \mathrm{C}$. Extract samples were evaluated at a final concentration of $0.1 \mathrm{mg} / \mathrm{mL}$. Total content of flavonols was expressed in terms of quercetin equivalent, QUE (standard curve equation: $y=0.0255 x+0.0069, R^{2}$ $=0.9995), \mathrm{mg}$ of $\mathrm{QU} / \mathrm{g}$ of dry extract.

\section{Determination of total proanthocyanidins}

Determination of proanthocyanidins was based on the procedure reported by Sun et al. [25]. A volume of $0.5 \mathrm{ml}$ of $0.1 \mathrm{mg} / \mathrm{mL}$ extract solution was mixed with $3 \mathrm{ml}$ of $4 \%$ vanillin-methanol solution and $1.5 \mathrm{ml}$ hydrochloric acid; the mixture was allowed to stand for 15 minutes. The absorbance was measured at $500 \mathrm{~nm}$. Extract samples were evaluated at a final concentration of $0.1 \mathrm{mg} / \mathrm{mL}$. Total content of proanthocyanidin was expressed in terms of catechin equivalent, CAE (standard curve equation: $\left.y=0.567 x-0.024, R^{2}=0.9801\right)$, $\mathrm{mg}$ of $\mathrm{CA} / \mathrm{g}$ of dry extract.

\section{Determination of total antioxidant capacity}

Total antioxidant capacity (TAC) of samples was determined by the method reported by Prieto et al. [26] with some modifications. $0.5 \mathrm{ml}$ of samples/standard at different concentrations was mixed with $3 \mathrm{ml}$ of reaction mixture containing $0.6 \mathrm{M}$ sulphuric acid, $28 \mathrm{mM}$ sodium phosphate and $1 \%$ ammonium molybdate into the test tubes. The test tubes were incubated at $95^{\circ} \mathrm{C}$ for $10 \mathrm{~min}$ utes to complete the reaction. The absorbance was measured at $695 \mathrm{~nm}$ using a spectrophotometer against blank after cooling at RT. Catechin was used as standard. A typical blank solution contained $3 \mathrm{ml}$ of reaction mixture and the appropriate volume of the same solvent used for the samples/standard was incubated at $95^{\circ} \mathrm{C}$ for 10 minutes and the absorbance was measured at $695 \mathrm{~nm}$. Increased absorbance of the reaction mixture indicated increase total antioxidant capacity.

\section{Ferrous reducing antioxidant capacity assay}

The ferrous reducing antioxidant capacity (FRAC) of samples was evaluated by the method of Oyaizu [27]. $0.25 \mathrm{ml}$ samples/standard solution at different concentration, $0.625 \mathrm{ml}$ of potassium buffer $(0.2 \mathrm{M})$ and $0.625 \mathrm{ml}$ of $1 \%$ potassium ferricyanide, $\left[\mathrm{K}_{3} \mathrm{Fe}(\mathrm{CN})_{6}\right]$ solution were added into the test tubes. The reaction mixture was incubated for 20 minutes at $50^{\circ} \mathrm{C}$ to complete the reaction. Then $0.625 \mathrm{ml}$ of $10 \%$ trichloro acetic acid, TCA solution was added into the test tubes. The total mixture was centrifuged at $3000 \mathrm{rpm}$ for 10 minutes. After which, $1.8 \mathrm{ml}$ supernatant was withdrawn from the test tubes and was mixed with $1.8 \mathrm{ml}$ of distilled water and $0.36 \mathrm{ml}$ of $0.1 \%$ ferric chloride $\left(\mathrm{FeCl}_{3}\right)$ solution. The absorbance of the solution was measured at $700 \mathrm{~nm}$ using a spectrophotometer against blank. A typical blank solution contained the same solution mixture without plant extracts/standard and it was incubated under the same conditions and the absorbance of the blank solution was measured at $700 \mathrm{~nm}$. Increased absorbance of the reaction mixture indicated increase reducing capacity.

\section{DPPH radical scavenging assay}

Free radical scavenging ability of the extracts was tested by DPPH radical scavenging assay (DRSA) as described by Choi et al. [28] and Desmarchelier et al. [29]. A solution of $0.1 \mathrm{mM}$ DPPH in methanol was prepared and $2.4 \mathrm{ml}$ of this solution was mixed with $1.6 \mathrm{ml}$ of extract in methanol at different concentration. The reaction mixture was vortexed thoroughly and left in the dark at RT for 30 minutes. The absorbance of the mixture was measured spectrophotometrically at $517 \mathrm{~nm}$. BHT was used as reference. Percentage DPPH radical scavenging 
activity (\% DRSA) was calculated by the following equation,

$$
(\% \mathrm{DRSA})=\left\{\left(A_{o}-A_{1}\right) / A_{o}\right\} \times 100
$$

Where $A_{0}$ is the absorbance of the control, and $A_{1}$ is the absorbance of the extractives/standard.

Then \% of inhibition was plotted against concentration, and from the graph $\mathrm{IC}_{50}$ was calculated.

\section{Hydroxyl radical scavenging activity}

Hydroxyl radical scavenging activity (HRSA) of the extractives was determined by the method of Klein et al. [30] with a slight modification. $0.5 \mathrm{ml}$ of extractives/ standard at different concentration was taken in test tubes. $1 \mathrm{ml}$ of Fe-EDTA solution (0.13\% ferrous ammonium sulphate and $0.26 \%$ EDTA), $0.5 \mathrm{ml}$ of $0.018 \%$ EDTA solution, $1 \mathrm{ml}$ of $0.85 \%$ DMSO solution and $0.5 \mathrm{ml}$ of $22 \%$ ascorbic acid were added into the test tubes. The test tubes were capped tightly and warm at $85^{\circ} \mathrm{C}$ for 15 minutes into the water bath. After incubation, the test tubes were uncapped and $0.5 \mathrm{ml}$ ice cold TCA (17.5\%) was added to each of test tubes immediately. $3 \mathrm{ml}$ of nash reagent $(7.5 \mathrm{gm}$ of ammonium acetate, $300 \mu \mathrm{l}$ glacial acetic acid and $200 \mu \mathrm{l}$ acetyl acetone were mixed and made up to $100 \mathrm{ml}$ ) was added to all the tubes and incubated at RT for 15 minutes. Absorbance was taken in UV-spectrophotometer at $412 \mathrm{~nm}$ wave length. Percentage hydroxyl radical scavenging (\% HRSA) activity was calculated using the following equation,

$$
\% \mathrm{HRSA}=\left\{\left(A_{o}-A_{1}\right) / A_{o}\right\} \times 100
$$

Where $A_{0}$ is the absorbance of the control, and $A_{1}$ is the absorbance of the extractives/standard.

Then \% of inhibition was plotted against concentration, and from the graph $\mathrm{IC}_{50}$ was calculated.

\section{Lipid peroxidation inhibition assay}

The lipid peroxidation inhibition assay (LPI) was determined according to the method described by Liu et al. [31] with a slight modification. Excised rat liver was homogenized in buffer and then centrifuged to obtain liposome. $0.5 \mathrm{ml}$ of supernatant, $100 \mu \mathrm{l} 10 \mathrm{mM} \mathrm{FeSO}_{4}$, $100 \mu \mathrm{l} 0.1 \mathrm{mM} \mathrm{AA}$ and $0.3 \mathrm{ml}$ of extractives or standard at different concentration were mixed to make the final volume $1 \mathrm{ml}$. The reaction mixture was incubated at $37^{\circ} \mathrm{C}$ for 20 minutes. $1 \mathrm{ml}$ of (28\%) TCA and $1.5 \mathrm{ml}$ of (1\%) TBA was added immediately after heating. Finally, the reaction mixture was again heated at $100^{\circ} \mathrm{C}$ for 15 minutes and cool at RT. After cooling, the absorbance was taken at $532 \mathrm{~nm}$. Percentage inhibition of lipid peroxidation (\% LPI) was calculated by the following equation,

$$
\% \mathrm{LPI}=\left\{\left(A_{o}-A_{1}\right) / A_{o}\right\} \times 100
$$

Where $A_{0}$ is the absorbance of the control, and $A_{1}$ is the absorbance of the extractives/standard.

Then $\%$ of inhibition was plotted against concentration, and from the graph $\mathrm{IC}_{50}$ was calculated.

\section{Statistical analysis}

All analyses were carried out in triplicates. Data were presented as mean $\pm \mathrm{SD}$. To evaluate significant relationships between experimental parameters by correlation and regression analysis, the $F$ - and $t$-tests ( $\mathrm{p}$-value $<0.001$ ) were used. Free R-software version 2.15.1 (http://www.r-project. org/) and Microsoft Excel 2007 (Roselle, IL, USA) were used for the statistical and graphical evaluations.

\section{Results}

\section{Determination of TAC and FRAC}

The TAC and FRAC of methanolic extractives of different parts of Tut plant were shown in Table 1. Methanolic extract of different parts of Tut plant showed considerable antioxidant activity compared to CA (standard). At the concentration of $100 \mu \mathrm{g} / \mathrm{mL}$, the absorbance of methanolic extract of TL, TF, TSB, TRB and (+)-catechin were $0.148,0.410,0.684,0.466$ and 1.81 , respectively; while at $400 \mu \mathrm{g} / \mathrm{mL}$, the absorbance of methanolic extracts of TL, TF, TSB, TRB and (+)-catechin were 0.532, 0.916, 2.316, 1.690 and 3.875 . The extractives were found to increase the total antioxidant activity with the increasing concentration of the extracts (Table 1).

The methanolic extracts of four parts of Tut plant showed reducing activity, although less than that of ascorbic acid, a reference antioxidant, the extractives increased the reducing activity with the increased concentration of the extracts. At $100 \mu \mathrm{g} / \mathrm{mL}$, the absorbance of methanolic extracts of TL, TF, TSB, TRB and ascorbic acid were $0.516,0.088,0.555,0.659$ and 2.47 respectively, while at $400 \mu \mathrm{g} / \mathrm{mL}$, the absorbance of methanolic extracts of TL, TF, TSB, TRB and AA were 1.152, 0.355, 2.454, 2.149 and 3.04, respectively. A higher absorbance indicates a higher reducing power. These results demonstrated that the methanolic extracts of TSB and TRB had considerable iron reducing capacity.

\section{DPPH radical scavenging activity}

Figure 1A shows the dose-response curve of DPPH radical scavenging activity of the methanolic extracts of TL, TF, TSB and TRB of Tut plant, compared with BHT. It was observed that the extract of TSB had higher activity than that of the other extractives. At a concentration of $100 \mu \mathrm{g} / \mathrm{mL}$, the scavenging activity of the TL, TF, TSB 
Table 1 Absorbance of TAC and FRAC of different parts (TL, TF, TSB and TRB) of Tut. at different concentration

\begin{tabular}{lcccc}
\hline Extractives & \multicolumn{2}{c}{ TAC } & \multicolumn{2}{c}{ FRAC } \\
\cline { 2 - 5 } & At $\mathbf{1 0 0} \boldsymbol{\mu \mathbf { g } / \mathbf { m L }}$ & At $\mathbf{4 0 0} \boldsymbol{\mu \mathbf { g } / \mathbf { m L }}$ & At $\mathbf{1 0 0} \boldsymbol{\mu \mathbf { g } / \mathbf { m L }}$ & At $\mathbf{4 0 0} \boldsymbol{\mu \mathbf { g } / \mathbf { m L }}$ \\
\hline TL & $0.148 \pm 0.011^{1}$ & $0.532 \pm 0.011$ & $0.516 \pm 0.027$ & $1.152 \pm 0.039$ \\
TF & $0.410 \pm 0.019$ & $0.916 \pm 0.016$ & $0.088 \pm 0.009$ & $0.355 \pm 0.013$ \\
TSB & $0.684 \pm 0.026$ & $2.316 \pm 0.031$ & $0.555 \pm 0.025$ & $2.454 \pm 0.193$ \\
TRB & $0.466 \pm 0.014$ & $1.690 \pm 0.017$ & $0.659 \pm 0.014$ & $2.149 \pm 0.064$ \\
AA & - & - & $2.47 \pm 0.008$ & $3.04 \pm 0.163$ \\
CA & $1.81 \pm 0.041$ & $3.875 \pm 0.081$ & - & - \\
\hline$N B:{ }^{1}$ Each value is the average of three analyses \pm standard deviation. $T L=$ Tut leaf, $T F=$ Tut fruit, $T S B=$ Tut stem bark, $T R B=$ Tut root bark, $A A=$ Ascorbic acid
\end{tabular}

and TRB reached 28.57, 62.75, 94.88 and $82.74 \%$, while at the same concentration, that of the BHT was 96.354\%. The $\mathrm{IC}_{50}$ of methanolic extracts of TL, TF, TSB and TRB were $108.69,76.00,36.50$ and $41.00 \mu \mathrm{g} / \mathrm{ml}$, respectively. The $\mathrm{IC}_{50}$ of $\mathrm{BHT}$ (standard) was $8.5 \mu \mathrm{g} / \mathrm{mL}$ (Figure 1A).

\section{Hydroxyl radical scavenging activity}

The hydroxyl radical scavenging activity of the methanolic extracts of the TL, TF, TSB and TRB of Tut plant possess dose-response curve, compared with CA. It was observed that extract of the TSB had higher activity than that of the other extractives. At a concentration of $200 \mu \mathrm{g} / \mathrm{mL}$, the scavenging activity of the TL, TF, TSB and TRB reached 47.23, 56.48, 81.10 and $74.21 \%$, while at the same concentration, that of the CA was $81.07 \%$. The hydroxyl radical scavenging activity of TSB of Tut plant was closely resembled to that of $\mathrm{CA}$. The $\mathrm{IC}_{50}$ of methanolic extracts of TL, TF, TSB and TRB were 211.72, 177.05, 57.25 and 116.00 $\mu \mathrm{g} / \mathrm{mL}$, respectively. The $\mathrm{IC}_{50}$ of $\mathrm{CA}$ (standard) was $27.5 \mu \mathrm{g} / \mathrm{mL}$ (Figure 1B).

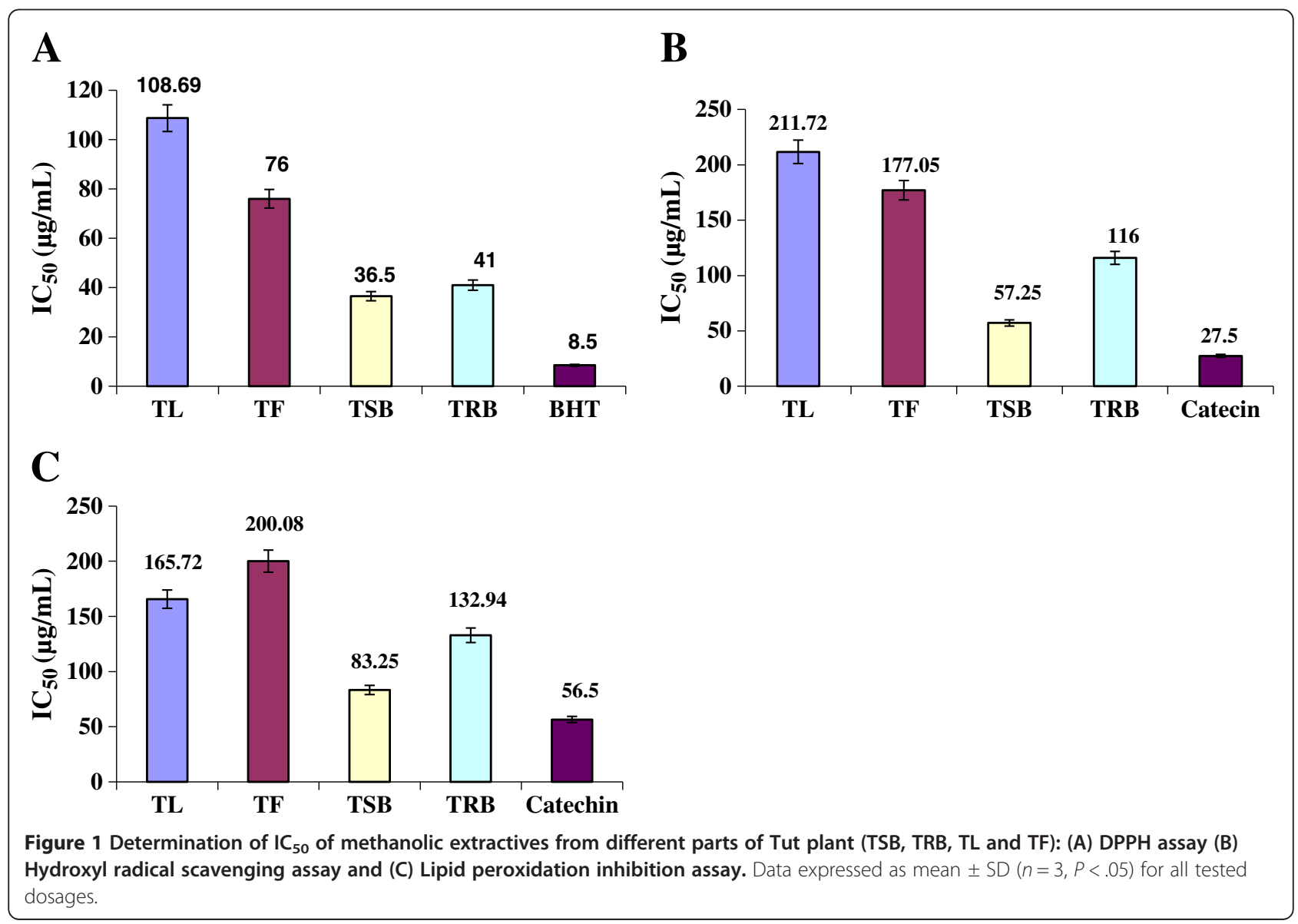


Table 2 Polyphenols content of the methanolic extracts of TL, TF, TSB and TRB

\begin{tabular}{lccrr}
\hline Polyphenols & TL & TF & \multicolumn{1}{c}{ TSB } & \multicolumn{1}{c}{ TRB } \\
\hline Phenolics $^{a}$ & $103.68 \pm 17.47^{1}$ & $52.71 \pm 3.17$ & $285.62 \pm 2.54$ & $165.27 \pm 3.28$ \\
Flavonoids $^{b}$ & $6.667 \pm 2.45$ & $4.198 \pm 2.26$ & $102.469 \pm 6.19$ & $12.59 \pm 2.96$ \\
Flavonols $^{c}$ & $185.48 \pm 1.19$ & $149.01 \pm 2.78$ & $220.38 \pm 1.26$ & $132.54 \pm 1.77$ \\
Proanthocyanidins $^{b}$ & $2.36 \pm 0.04$ & $1.94 \pm 0.25$ & $4.68 \pm 0.05$ & $3.33 \pm 0.07$ \\
\hline
\end{tabular}

$N B$ : ${ }^{1}$ Each value is the average of three analyses \pm standard deviation. $a, b$ and $c$ expressed in terms of GAE, CAE and QUE, respectively (mg of GA, CA and QU/g of dry extract, respectively).

\section{Lipid peroxidation inhibition assay}

The lipid peroxidation inhibition activity of the methanolic extracts of TL, TF, TSB and TRB of Tut plant was compared with CA. The methanolic extract of TSB had higher activity than that of the other extractives. At a concentration of $200 \mu \mathrm{g} / \mathrm{mL}$, the scavenging activity of the TL, TF, TSB and TRB reached 30.67, 25.77, 61.51 and $43.12 \%$, while at the same concentration, that of the catechin was $65.54 \%$. The $\mathrm{IC}_{50}$ of methanolic extracts of TL, TF, TSB and TRB were 165.72, 200.08, 83.25 and $132.94 \mu \mathrm{g} / \mathrm{mL}$, respectively. The $\mathrm{IC}_{50}$ of catechin (standard) was $56.5 \mu \mathrm{g} / \mathrm{mL}$ (Figure $1 \mathrm{C}$ ).

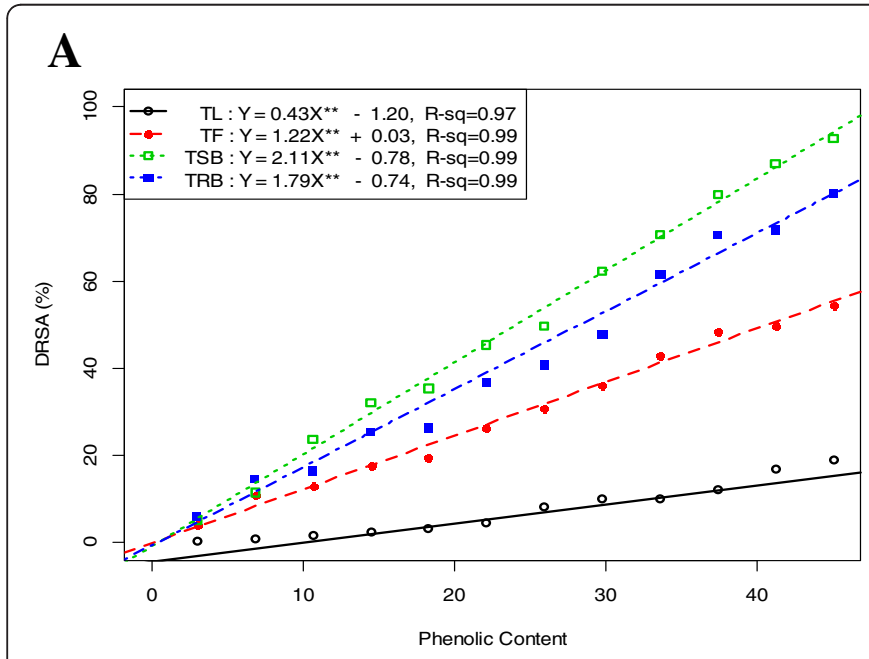

B

C
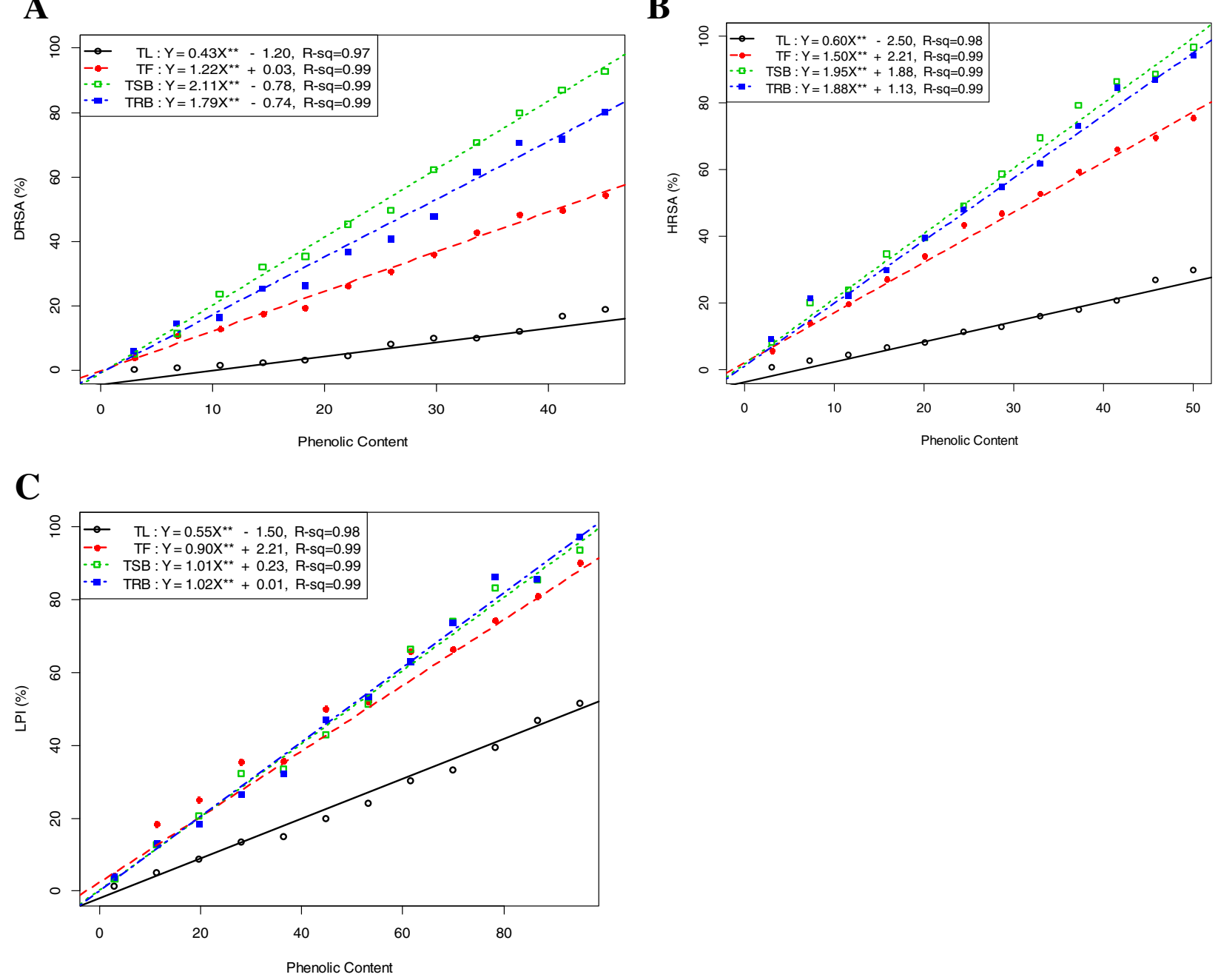

Figure 2 Relationship of total phenolic contents with (A) \% DRSA, (B) \% HRSA and (C) \% LPI. Data expressed as mean \pm SD $(n=3$, $P<.001)$. 
Total phenolic, flavonoids, flavonol and proanthocyanidin contents

Table 2 shows the total polyphenols in the methanolic extract of TL, TF, TSB and TRB. Correlation of total phenolic contents of the extractives with free radical $\left(\mathrm{DPPH}^{*}\right.$ and $\left.{ }^{\circ} \mathrm{OH}\right)$ scavenging efficiencies and \%LPI are shown in Figure 2.

\section{Correlation and regression of LPI with DRSA and HRSA}

Figure 3 represents the correlation and regression ( $p$-value $<0.001)$ of LPI with DRSA and HRSA. Significant correlations $(p$-value $<0.001)$ were observed for all the extractives (Figure 3).

\section{Discussion}

Total antioxidant property and ferrous reducing antioxidant property

The antioxidant potentials of the different parts of methanolic extracts of Tut plant were estimated from their ability to reduce the reduction of Mo (VI) to Mo (V) by the antioxidant compounds and subsequent formation of a green phosphate/Mo (V) complex at acidic $\mathrm{pH}$. The reducing ability of the extractives was in the range of $0.532 \pm 0.011-2.316 \pm 0.031 \mu \mathrm{m}$ green phosphate/Mo (V) (Table 1). Antioxidant activity increased proportionally with the increase of polyphenols content. According to recent reports, a highly positive relationship between total phenols and antioxidant activity appears to be the trend in many plant species [32]. The iron reducing capacity of the methanolic extractives of TL, TF, TSB and TRB were estimated from their ability to reduce the $\mathrm{Fe}^{3+}$-ferricyanide complex to the ferrous form by donating an electron. The reducing ability of the extractives was in the range of $0.355 \pm 0.013-2.149 \pm$ $0.064 \mu \mathrm{m} \mathrm{Fe}(\mathrm{II}) / \mathrm{g}$ (Table 1). In this study, ferrous reducing antioxidant capacity was increased with the increase of phenolic contents. Our results are consistent with the result published previously [33].

\section{DPPH radical scavenging activity}

The effect of antioxidants on DPPH is thought to be due to their hydrogen donating ability [34]. Radical scavenging activities are very important to prevent the deleterious role of free radical in different diseases including cancer. DPPH free radical scavenging is an accepted mechanism by which antioxidants act to inhibit lipid peroxidation. This method has been used extensively to predict antioxidant activities because of the relatively short time required for analysis. Our results revealed that the methanolic extract of TSB had the similar free radical scavenging activity when compared with standard BHT (Figure 1A). The results indicated the protondonating ability of the extractives which could serve as free radical inhibitors or scavengers and can also be served as primary antioxidants. The work performed adequately demonstrates that there exists correlation between polyphenolic contents of the extractives and its anti-oxidant properties. Consequently, this could be exploited as health care supplement [33].

\section{Hydroxyl radical scavenging activity}

The mutagenic capacity of free radicals is due to the direct interactions of hydroxyl radicals with DNA and therefore playing an important role in cancer formation [35]. Hydroxyl radicals can be generated by biochemical reaction. Superoxide radical is converted by superoxide dismutase to hydrogen peroxide, which can subsequently produce extremely reactive hydroxyl radicals in the presence of divalent metal ions, such as iron and copper. The results demonstrated that the methanolic extract of

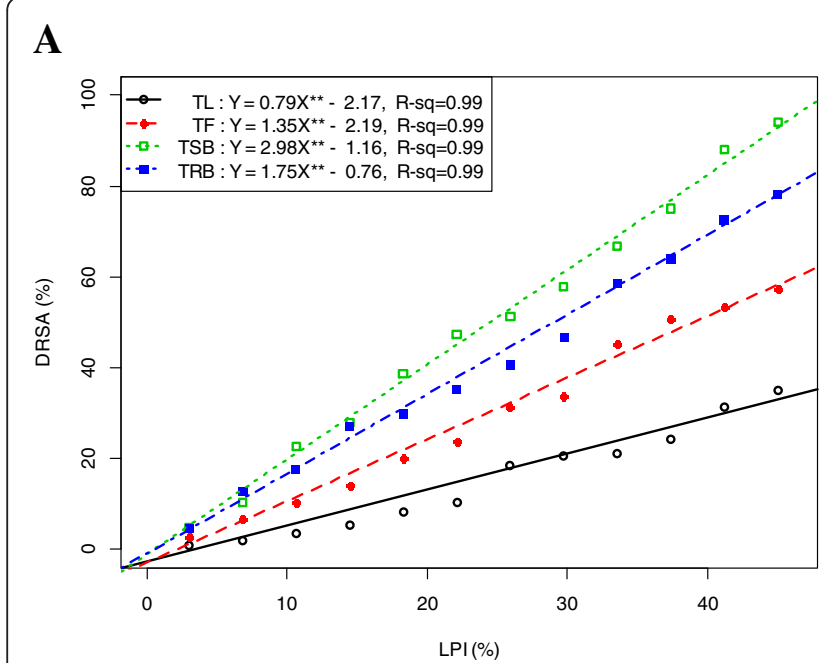

B

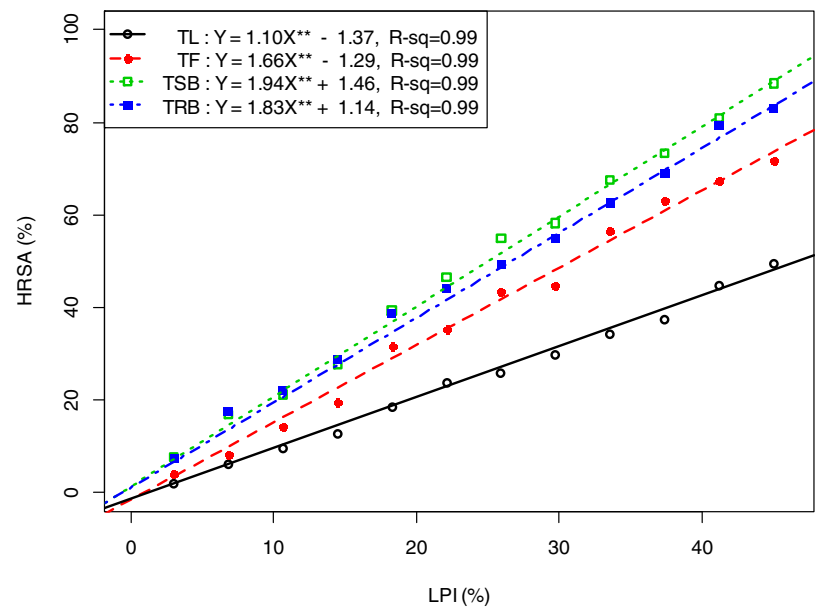

Figure 3 Relationship of \% LPI with (A) \% DRSA and (B) \% HRSA. Data expressed as mean \pm SD $(n=3, P<.001)$ 
four parts TL, TF, TSB and TRB had appreciable hydroxyl radical scavenging activity when compared with standard antioxidant, catechin (Figure 1B) and could be served as anticancer agent by inhibiting the interaction of hydroxyl radical with DNA. The ability of the extracts to quench hydroxyl radicals might directly relate to the prevention of lipid peroxidation.

\section{Lipid peroxidation inhibition assay}

ROS induce membrane damage by peroxidising lipid moiety, specially the polyunsaturated fatty acids with a chain reaction known as lipid peroxidation [36]. The initial reaction generates a second radical, which in turn can react with a second macromolecule to continue the chain reaction leads to functional abnormalities of cells. In this study, lipid peroxidation of rat liver homogenates was induced by ferric ion plus ascorbic acid. Lipid peroxidation inhibition activity of TSB was found to be higher than other extractives (Figure 1C). These results indicated that Tut plant extracts have potential to be studied for use in treating liver disease.

\section{Total phenolic, flavonoids, flavonols and proanthocyanidin contents}

Total phenolic contents of the extractives showed significant and strong positive correlation $(p$-value $<.001)$ with free radical $\left(\mathrm{DPPH}^{*}\right.$ and $\left.{ }^{\circ} \mathrm{OH}\right)$ scavenging efficiencies and \%LPI (Figure 2). These results suggest a probable paramount role that the polyphenolic constituents of the extracts might play in free radical neutralization and lipid peroxidation inhibition.

\section{Correlation and regression of LPI with DRSA and HRSA}

Significant correlations $(p$-value $<0.001)$ were observed for all the extractives for all dosages (Figure 3). This infers that the extractives differentially inhibit lipid peroxidation by virtue of their varying degrees of free radical quenching potential.

\section{Conclusion}

The different parts of Tut plant have been used to treat a variety of diseases in Bangladesh as folk medicine. Compared to the effects of leaf, root and stem barks and ripe seeds on different diseases, little is known about the antioxidant activities of different parts of Tut plant. Our results clearly showed that the methanolic extract of TSB had strong hydroxyl and DPPH radical scavenging activities. The reducing capacity of TSB on ferrous ion was higher than that of other extractives. In addition, the potent antioxidative activity of Tut plant might result from its high contents of polyphenolic compounds. Hence, the methanolic extract from different parts of Tut plant could be used as a health-care food supplement and in the pharmaceutical industry.

\section{Additional file}

Additional file 1: Figure S1. Matured Morus alba L. (Moraceae) plant (locally known as Tut). Picture was taken on October, 2010 from botanical garden, Rajshahi University, Bangladesh.

\begin{abstract}
Abbreviations
AA: Ascorbic acid; CA: Catechin; CAE: Catechin equivalent; DPPH: 1,1diphenyl-2-picrylhydrazine; DRSA: DPPH radical scavenging assay; FRAC: Ferrous reducing antioxidant capacity; GA: Gallic acid; GAE: Gallic acid equivalent; HRSA: Hydroxyl radical scavenging activity; LPI: Lipid peroxidation inhibition assay; OS: Oxidative stress; QU: Quercetin; QUE: Quercetin equivalent; ROS: Reactive oxygen species; RT: (Room Temperature); TAC: Total antioxidant capacity; TCA: Trichloro acetic acid; TF: Tut fruits; TL: Tut leaves; TRB: Tut root barks; TSB: Tut stem barks.
\end{abstract}

\section{Competing interests}

The authors declare that they have no competing interests.

\section{Authors' contributions}

MAK: Designed the study and carried out the tests under the supervision of AHMKA. AAR: Helped to carry out the assay and draft the manuscript. SI: Carried out the lipid peroxidation inhibition assay. PK: Checked the grammatical errors and corrected the final manuscript. SP: Helped to carry out the assay. MBI: Helped to do the extraction. MH: Collected samples and provided solvent for extraction. MR: Helped to carry out the assay. GS: Helped to coordinate the biological assay. SN: Confirmed the antioxidant assay. MNHM: Performed statistical (correlation and regression) analysis. All authors read and approved the final manuscript.

\section{Acknowledgment}

The authors acknowledge the Bangladesh Council of Scientific and Industrial Research (BCSIR) for financial support. We also thank to Dr. AHM Mahabubur Rahman, Assistant Professor, Department of Botany, University of Rajshahi for the identification of the plant.

\section{Author details}

${ }^{1}$ Department of Pharmacy, University of Rajshahi, Rajshahi 6205, Bangladesh. ${ }^{2}$ Department of Pharmaceutical and Biological Sciences, UCL School of Pharmacy, London, UK. '3Senior Scientific Officer, BCSIR, Rajshahi 6205, Bangladesh. ${ }^{4}$ Department of Zoology, University of Rajshahi, Rajshahi 6205, Bangladesh. ${ }^{5}$ Department of Statistics, University of Rajshahi, Rajshahi 6205, Bangladesh.

Received: 2 October 2012 Accepted: 16 January 2013 Published: 19 January 2013

\section{References}

1. Gilgun-Sherki Y, Rosenbaum Z, Melamed E, Offen D: Antioxidant therapy in acute central nervous system injury: current state. Pharmacol Rev 2002, 54:271-284

2. Evans PH: Free radicals in brain metabolism and pathology. Br Med Bull 1993, 49:577-587.

3. Willett WC: Balancing life-style and genomics research for disease prevention. Science 2002, 296:695-698.

4. Steinmetz KA, Potter JD: Vegetables, fruit, and cancer prevention: a review. J Am Diet Assoc 1996, 96:1027-1039.

5. Kahkonen MP, Hopia Al, Vuorela HJ, Rauha JP, Pihlaja K, Kujala KS, Heinonen M: Antioxidant activity of plant extracts containing phenolic compounds. J Agric Food Chem 1999, 47:3954-3962.

6. Miliauskas G, Venskutonis PR, van Beek TA: Screening of radical scavenging activity of some medicinal and aromatic plant extracts. Food Chem 2004, 85:231-237.

7. Balasundram N, Sundram K, Samman S: Phenolic compounds in plants and agri-industrial by-products: Antioxidant activity, occurrence, and potential uses. Food Chem 2006, 99:191-203.

8. Singhal BK, Khan MA, Dhar A, Baqual FM, Bindroo BB: Approaches to industrial exploitation of mulberry (mulberry sp.) fruits. J Fruit Ornam Plant Res 2010, 18:83-99. 
9. Ercisli S, Orhan E: Chemical composition of white (Morus alba), red (Morus rubra) and black (Morus nigra) mulberry fruits. Food Chem 2007, 103:1380-1384.

10. Jaslin E, Sethuramani A, Devi P, Meera R: Anti diabetic, hypolipidemic and anti oxidant activities of the plant extracts of Morus alba Linn. Int J Phytopharm Res 2010, 1:25-28.

11. Sethuramani A, Devi P, Jaslin E, Meera R, Kameswari B: Pharmacognostical and preliminary phytochemical investigation on the leaves of Morus alba Linn. J Pharm Sci Res 2010, 2:513-517.

12. Sohn HY, Son KH, Kwon CS, Kwon GS, Kang SS: Antimicrobial and cytotoxic activity of 18 prenylated flavonoids isolated from medicinal plants: Morus alba L., Morus mongolica Schneider, Broussnetia papyrifera (L.) Vent, Sophora flavescens Ait and Echinosophora koreensis Nakai. Phytomed 2004, 11:666-672.

13. Abbasi AM, Khan MA, Ahmad M, Zafar M, Khan H, Muhammad N, Sultana S: Medicinal plants used for the treatment of jaundice and hepatitis based on socio-economic documentation. Afr J Biotec 2009, 8:1643-1650.

14. Yang $X$, Yang $L$, Zheng $H$ : Hypolipidemic and antioxidant effects of mulberry (Morus alba L.) fruit in hyperlipidaemia rats. Food Chem Toxicol 2010, 48:2374-2379.

15. Venkatesh KR, Chauhan S: Mulberry: Life enhancer. J Med Plants Res 2008, 2:271-278.

16. Mithun SR, Sampada S, Vineet M, Purti A: Herbal antidepressants. Int J Pharm Fron Res 2011, 1:159-169.

17. Katsube T, Yamasaki M, Shiwaku K, Ishijima T, Matsumoto I, Abe K, Yamasaki Y: Effect of flavonol glycoside in mulberry (Morus alba L.) leaf on glucose metabolism and oxidative stress in liver in diet-induced obese mice. J SCi Food Agr 2010, 90:2386-2392.

18. Kang TH, Oh HR, Jung SM, Ryu JH, Park MW, Park YK, Kim SY: Enhancement of neuroprotection of Mulberry leaves (Morus alba L.) prepared by the anaerobi. Biol Pharm Bull 2006, 29:270-274.

19. Naowaratwattana W, De-Eknamkul W, De-Mejia EG: Phenolic-containing organic extracts of Mulberry (Morus alba L.) leaves inhibit HepG2 Hepatoma cells through G2/M phase arrest, induction of apoptosis and inhibition of Topoisomerase lla activity. J Med Food 2010, 13:1045-1056.

20. Abdulla MA, Ali HM, Ahmed KAA, Noor SM, Ismail S: Evaluation of the antiulcer activities of Morus alba extracts in experimentally-induced gastric ulcer in rats. Biomed Res 2009, 20:35-39.

21. Alam AHMK, Rahman MAA, Baki MA, Rashid MH, Bhuyan MSA, Sadik G: Antidiarrhoeal principle of Achyranthes ferruginea Roxb. and their cytotoxicity. Ban Pharm J 2002, 12:1-4.

22. Wolfe K, Wu X, Liu RH: Antioxidant activity of apple peels. J Agr Food Chem 2003, 51:609-614.

23. Ordon-ez AAL, Gomez JD, Vattuone MA, Isla MI: Antioxidant activities of Sechium edule (Jacq.) Swart extracts. Food Chem 2006, 97:452-458.

24. Kumaran A, Karunakaran RJ: In vitro antioxidant activities of methanol extracts of Phyllanthus species from India. LWT- Food Sci Technol 2007, 40:344-352.

25. Sun JS, Tsuang YW, Chen IJ, Huang WC, Hang YS, Lu FJ: An ultra-weak chemiluminescence study on oxidative stress in rabbits following acute thermal injury. Burns 1998, 24:225-231.

26. Prieto P, Pineda M, Aguilar M: Spectrophotometric quantitation of antioxidant capacity through the formation of a phosphomolybdenum complex: specific application to the determination of vitamin E. Anal Bio 1999, 269:337-341.

27. Oyaizu M: Studies on products of browning reactions: antioxidant activities of products of browning reaction prepared from glucose amine. Jap J Nut 1986, 44:307-315.

28. Choi HY, Jhun EJ, Lim BO, Chung IM, Kyung SH, Park DK: Application of flow injection-chemilumineacence to the study of radical scavenging activity in plants. Phytother Res 2000, 14:250-253.

29. Desmarchelier C, Bermudez MJN, Coussio J, Ciccia G, Boveris A: Antioxidant and prooxidant activities in aqueous extract of Argentine plants. Int J Pharmcog 1997, 35:116-120.

30. Klein SM, Cohen G, Cederbaum Al: Production of formaldehyde during metabolism of dimethyl sulphoxide by hydroxyl radical generating system. Biochem 1981, 20:6006-6012.

31. Liu F, Ng TB: Antioxidative and free radical scavenging activities of selected medicinal herbs. Life Sci 2000, 66:725-735.
32. Oktay M, Gülçin I, Küfrevioglu Ol: Determination of in vitro antioxidant activity of fennel (Foeniculum vulgare) seed extracts. LWT-Food Sci Technol 2003, 36:263-271.

33. Huang D, Ou B, Prior RL: The chemistry behind antioxidant capacity assays. J Agric Food Chem 2005, 53:1841-1856.

34. Baumann J, Wurn G, Bruchlausen FV: Prostaglandin synthetase inhibiting $\mathrm{O}_{2}$ radical scavenging properties of some flavonoids and related Phenolic compounds. Deutsche pharmakologische gesellschaft abstracts of the 20th spring meeting. Arc Pharmacol 1979, 307:R1-R77. Naunyn-Schmiedebergs Abstract No: R27 cited in.

35. Scully C: Oral cancer: New insights into pathogenesis. Dent Update 1993, 20:95-100.

36. Klauning JE XUY, Isenberg JS, Bachowski S, Kolaja KL, Jianga J, Stevenson $\mathrm{DE}$, Waloorg EF: The role of oxidative stress in chemical carcinogenesis. Environ Health Perspect 1998, 106:289-333.

doi:10.1186/1756-0500-6-24

Cite this article as: Khan et al: A comparative study on the antioxidant activity of methanolic extracts from different parts of Morus alba L. (Moraceae). BMC Research Notes 2013 6:24.

\section{Submit your next manuscript to BioMed Central and take full advantage of:}

- Convenient online submission

- Thorough peer review

- No space constraints or color figure charges

- Immediate publication on acceptance

- Inclusion in PubMed, CAS, Scopus and Google Scholar

- Research which is freely available for redistribution 